\title{
Um olhar sobre o letramento sob a abordagem High/Scope
}

\author{
A look upon literacy \\ under the High/Scope approach
}

Una mirada sobre el letramento

bajo el enfoque High/Scope

\author{
KARINY LOUIZY AMORIM-VANDERLEI* \\ Universidade Federal de Alagoas, Arapiraca- AL, Brasil. \\ THAINY KLÉIA LIRA** \\ Universidade Federal de Alagoas, Maceió- AL, Brasil. \\ MARTHA MARIA MINERVINO*** \\ Universidade Federal de Alagoas, Arapiraca- AL, Brasil.
}

\begin{abstract}
RESUMO: Este artigo destina-se à descrição e reflexão sobre uma experiência em educação infantil realizada em uma instituição pública de ensino de Alagoas. Tomando por base a abordagem educacional americana High/Scope no estudo, será tematizada a articulação entre elementos desta abordagem e os processos de letramento. Partindo-se de uma concepção de aprendizagem pela ação - foco do currículo High/Scope - é proposta uma análise do 'brincar de faz-de-conta' dentro da perspectiva do letramento, apontando-se assim as contribuições deste entrelaçamento para o desenvolvimento da linguagem na criança.
\end{abstract}

* Mestre e Doutoranda do Programa de Pós-Graduação em Educação da Universidade Federal de Alagoas. Professora Assistente do Curso de Pedagogia da Universidade Federal de Alagoas, Campus Arapiraca. E-mail: <kariny.louizy@gmail.com>.

** Pedagoga e Mestre em Educação pelo Programa de Pós-Graduação em Educação da Universidade Federal de Alagoas. E-mail: <thainylira@gmail.com>.

*** Doutora em Educação pelo Programa de Pós-Graduação em Educação da Universidade Federal de Alagoas. Professora Adjunta do Curso de Pedagogia da Universidade Federal de Alagoas, Campus Arapiraca. E-mail: <marthaminervino@gmail.com>. 
Palavras-chave: Aprendizagem ativa. Educação infantil. Letramento.

\begin{abstract}
This article intendeds to describe and reflect on an experience in early childhood education carried out at a public educational institution in the state of Alagoas, Brazil. With a study based on the American High/Scope educational approach, the articulation between elements of this approach and the literacy processes will be discussed. From an action-learning perspective -High/Scope curriculum focus - an analysis of 'playing make-believe' is proposed within the perspective of literacy, thus pointing to the contributions of this interweaving to the development of language in the child.
\end{abstract}

Keywords: Active learning. Child education. Literature.

RESUMEN: Este artículo se destina a la descripción y reflexión sobre una experiencia en educación infantil realizada en una institución pública de enseñanza de Alagoas. Tomando como base el enfoque educacional estadounidense High/Scope, en el estudio se tematizará la articulación entre elementos de este enfoque y los procesos de letramento. Partiendo de una concepción de aprendizaje por la acción - foco del currículo High/ Scope - se propone un análisis del 'juego de roles' dentro de la perspectiva del letramento, apuntando así las contribuciones de este entrelazamiento para el desarrollo del lenguaje en el niño.

Palabras clave: Aprendizaje activo. Educación Infantil. Letramento.

\title{
Introdução
}

A preocupação com o brincar nas pedagogias da infância emerge notadamente 1 a partir do final do século passado, na década de 90, era da qualidade na 1 educação infantil. Desde aquelas mais remotas às mais atuais, todas essas pedagogias contêm concepções inovadoras sobre o brincar e a educação, as quais não eram veiculadas pelas culturas de seu tempo (KISHIMOTO, 2004).

Nesta perspectiva, o Referencial Curricular Nacional para a Educação Infantil (1998) destaca que

a brincadeira favorece a auto-estima das crianças, auxiliando-as a superar progressivamente suas aquisições de forma criativa. Brincar contribui, assim, para a interiorização de determinados modelos de adulto, no âmbito de grupos sociais diversos. Essas significações atribuídas ao brincar transformam-no em um espaço singular de constituição infantil (p. 27). 
A abordagem High Scope, sobre a qual se fundamenta a experiência que aqui será explicitada, já em seu projeto original traz essa compreensão, traduzindo-a pragmaticamente na assunção e atribuição de um lugar central à brincadeira em suas proposições pedagógicas.

Desenvolvida por David Weikart e sua equipe na década de 60, tal abordagem constitui-se em uma proposta americana ${ }^{1}$ de currículo para a educação infantil, que, inicialmente, objetivava ajudar crianças em idade pré-escolar, as quais se encontravam em situação de risco, a conquistar sucesso na escola e na sociedade. Estes propósitos, entretanto, aos poucos foram sendo ampliados para toda a faixa etária da educação infantil e séries iniciais do ensino fundamental, passando este modelo educacional, desde então, a ser mundialmente conhecido.

O curriculum High/Scope, de acordo com Brickman e Taylor (1996, p. 26), apresenta dois princípios centrais. O primeiro deles enfatiza o desenvolvimento pela própria criança de sua compreensão do mundo a partir do envolvimento ativo com pessoas, materiais e ideias, baseando-se, entre outras filiações teóricas, na perspectiva cognitivo-desenvolvimentista de Jean Piaget, o qual defende que todas as crianças aprendem de forma ativa, isto é, adquirem conhecimentos fazendo experiências com o mundo que as rodeia, de forma que a dimensão de sua compreensão do mundo é continuamente alterada e ampliada, como resultado de seus contatos diários com outros indivíduos, com materiais e ideias.

O segundo princípio refere-se ao papel dos adultos que ensinam ou orientam crianças, o qual deve pautar-se em uma postura 'apoiante', favorecendo-lhes a construção de sua própria compreensão do mundo. Este princípio sustenta-se em um dos pressupostos básicos da teorização proposta por Vygotsky, desde o qual o ser humano constitui-se enquanto tal na sua relação com os demais, assumindo a linguagem, nesta concepção, uma posição de centralidade.

Isto posto, na plataforma metodológica do High/Scope - assim como, entendemos, deve acontecer em qualquer proposta que abranja o trabalho com a educação infantil o desenvolvimento da linguagem em suas múltiplas dimensões evidencia-se como um dos elementos essenciais, conferindo sobretudo um norteamento à ação educativa.

No que toca especificamente à linguagem em sua modalidade oral e escrita, na perspectiva da abordagem referida, seu desenvolvimento se dá de forma gradual, destituindo-se, neste ponto, de uma preocupação formal com resultados finais e focalizando-se o transcorrer do processo. Conforme explica Maehr (apud BRICKMAN e TAYLOR, 1996, p.77), “à medida que as crianças vão tomando consciência da utilidade da escrita, mesmo de formas não convencionais, vão se sentindo estimuladas para desenvolver capacidades de expressão verbal e escrita". Desta asserção, depreende-se a necessidade de um contato da criança com materiais e práticas em que estas linguagens possam ganhar significado. 
Com efeito, a proposta educacional do High/Scope centra-se em experiências de aprendizagem que produzam sentido para as crianças, desvinculando-se em especial de exercícios de repetição tomados isoladamente. Neste viés, são desenvolvidas estratégias para auxiliar e subsidiar às crianças um aprendizado, por si próprias, do ler e do escrever, o que preconiza a promoção da interação com os materiais escritos, bem como a participação em atividades nas quais seu uso seja representativo de suas reais funções na sociedade.

Ora, em uma sociedade grafocêntrica como a nossa, torna-se essencial saber fazer uso do ler e do escrever para além daquelas práticas identificadas com a mera decodificação de itens linguísticos. Em consonância com uma tal reflexão, sugere-nos Soares (1996, p. 85):

[...] do ponto de vista individual, o aprender a ler e escrever - alfabetizar-se, deixar de ser analfabeto, tornar-se alfabetizado, adquirir a "tecnologia" do ler e escrever e envolver-se nas práticas sociais de leitura e de escrita - tem consequências sobre o indivíduo, e altera seu estado ou condição em aspectos sociais, psíquicos, culturais, políticos, cognitivos, linguísticos e até mesmo econômicos; do ponto de vista social, a introdução da escrita em um grupo até então ágrafo tem sobre esse grupo efeitos de natureza social, cultural, política, econômica, linguística. [...] É esse, pois, o sentido que tem letramento [...]. Letramento é, pois, o resultado da ação de ensinar ou de aprender a ler e escrever: o estado ou a condição que adquire um grupo social ou um indivíduo como consequência de ter-se apropriado da escrita.

Também Calil (2004), em estudo sobre os efeitos do processo de letramento nas produções orais e escritas de crianças, assinala a importância de sua imersão no universo letrado que lhe é circundante, assim como em sua cultura, sendo esta marcadamente atravessada pela escrita. A este propósito, sublinha o autor:

em uma sociedade letrada, os eventos de letramento são múltiplos e o sujeito está imerso em diferentes situações de uso significativo da leitura e da escrita [...]. É de fundamental importância que os objetos impressos sejam investidos de significação através de práticas discursivas interacionais e que deles emanem dizeres, discursos, textos, letras..., tendo a voz do outro como elemento viabilizador (p. 335).

$E ́$, pois, associando-nos a este conjunto de concepções e posicionamentos, e reconhecendo a importância que adquirem esses dois eixos - o brincar e o letramento -, notadamente no trabalho com a educação infantil, que pretendemos fazer eco a respeito dos benefícios advindos de sua articulação no sentido do desenvolvimento da linguagem nas crianças. Neste trabalho serão expostos os resultados de uma experiência de estágio vivenciada em uma instituição municipal de educação infantil da cidade de Maceió, em Alagoas, realizada entre os meses de março a junho de 2009, envolvendo três turmas de crianças entre 3 e 5 anos de idade, sendo uma turma caracterizada como $1^{\circ}$ período e as outras duas como $2^{\underline{0}}$ período. 


\section{Recriando "espaços" para a aprendizagem}

O trabalho educacional na perspectiva da abordagem High/Scope pressupõe a organização de um espaço planejado e equipado de modo a apoiar possibilidades variadas do brincar. A ambiência propícia ao desencadeamento de uma aprendizagem ativa contempla, nesta proposta, a divisão espacial em áreas de interesses bem distintas, de maneira a encorajar as crianças a se lançarem sobre brincadeiras diversas. Explicam-nos Talbot e Frosta (apud HOHMANN e WEIKART, 1997, p. 161):

Quando um objeto ou ambiente é aberto a diferentes possibilidades de interpretação e uso, a criança passa a deter o poder de definir o que ele é ou para que serve, em vez de, esteriotipadamente, identificar uma maneira "correta" de o entender ou de sobre ele agir.

Tendo em vista estes delineamentos, durante a experiência realizada na instituição, nosso passo inicial consistiu exatamente na reorganização de uma "Sala de Áreas"² ali já existente graças ao trabalho de uma equipe que realizou estágio na escola, sob este mesmo referencial, anteriormente a nós. Ao final desta etapa reorganizacional, que objetivava proporcionar espaços mais amplos de deslocamento, assim como promover maior acessibilidade aos diversos materiais da sala para as crianças, o ambiente ficou dividido em cinco 'áreas de interesses' ${ }^{3}$ : "leitura”, "casinha", "blocos", "brinquedos" e "artes", cada uma delas com seus respectivos materiais.

\section{Figura 1: Layout da Sala de Áreas antes de nossa intervenção}

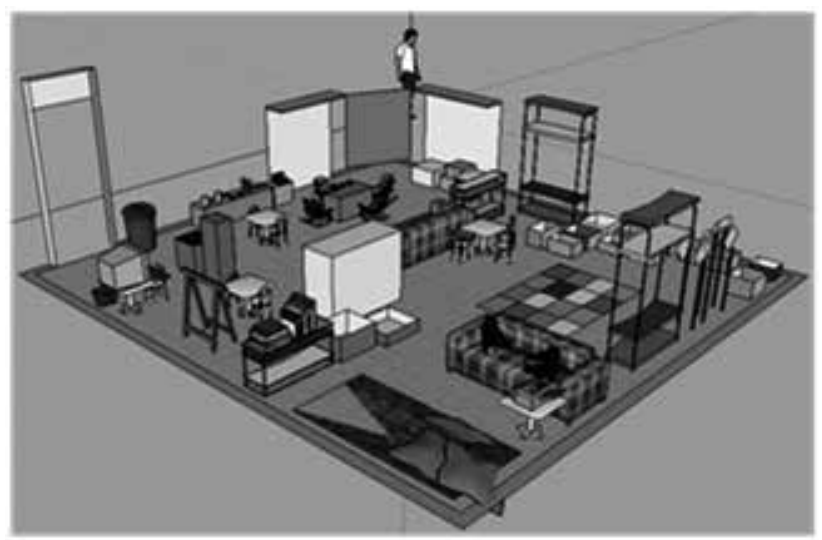


Figura 2: Layout da Sala de Áreas antes e depois da reorganização

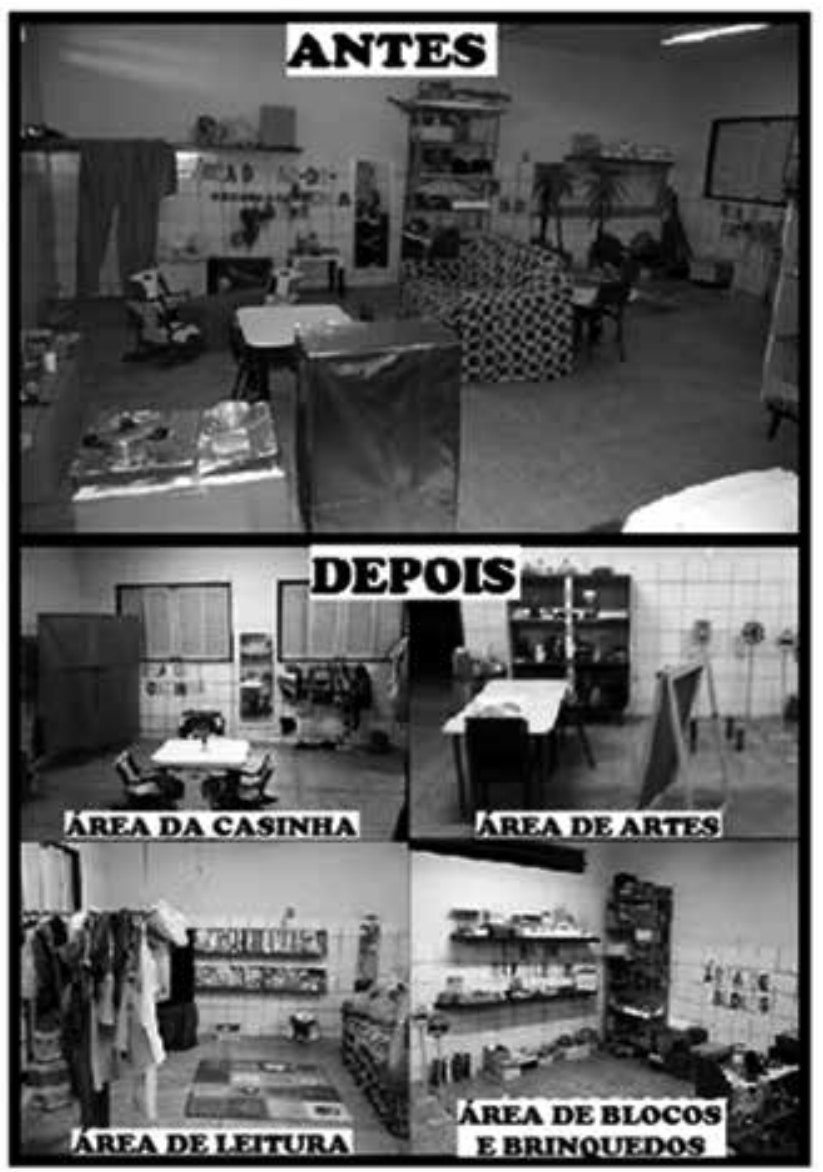

Na etapa subsequente, nos detivemos na consolidação da proposta referente àquela sala, introduzindo de início, com as turmas do $1^{0}$ e $2^{2}$ s períodos, a rotina prescrita na abordagem High/Scope, na qual prefigura um dispositivo trinitário central: o ciclo planejar-fazer- rever, que representa uma ferramenta de grande importância no suporte à aprendizagem da criança, englobando todos os elementos necessariamente contidos no 'aprender pela ação', quais sejam, materiais, manipulação, escolha, linguagem das crianças e apoio dos adultos.

O livro Educar a Criança (HOHMANN e WEIKART, 1997), referência base da abordagem High/Scope, traz a seguinte afirmação acerca deste momento:

Ao fazer planos diários, ao segui-los e, depois, ao relembrar aquilo que fizeram, as crianças pequenas aprendem a articular as suas intenções e a refletir sobre as suas ações. Também começam a perceber que têm boas capacidades para pensar, tomar decisões e resolver problemas (p. 247). 
O procedimento inicial da sequência planejar-fazer-rever é o planejamento. Neste momento, estimula-se a criança à articulação e expressão de suas ideias, escolhas e decisões, bem como busca-se uma promoção de sua autoconfiança e seu sentido de controle. $\mathrm{O}$ 'planejar' possibilita às crianças se envolverem de modo mais intenso nas brincadeiras; por este recurso, ainda, torna-se perceptível um direcionamento das ações da criança para atividades lúdicas progressivamente mais complexas.

Consecutivamente, dá-se o tempo de trabalho, que é correspondente ao 'fazer' na sequencia referida. Tal momento diz respeito a um período de tempo pré-estabelecido, no qual as crianças podem pôr em ação suas intenções de brincadeiras, isto é, as atividades nas quais pensaram de antemão e descreveram durante o planejamento inicial. Ao mesmo tempo, as crianças podem prosseguir com ideias novas e planos paralelos enquanto brincam (HOHMANN e WEIKART, 1997). Este procedimento é também fundamental na rotina da abordagem High/Scope, com vistas ao favorecimento de um desenvolvimento multidimensional.

Neste contexto, às crianças é possibilitado concretizarem seu brincar - fazendo-o de forma previamente refletida, mas, com abertura constante a novas possibilidades e configurações -, interagir em pares ou com o grupo, resolver problemas surgidos neste espaço de tempo, participar em diferentes conjunturas e papéis através dos ambientes temáticos sociais reproduzidos na sala, e, por tudo isso, construir conhecimentos significativamente.

É importante salientar que, especialmente durante o tempo de trabalho, o apoio dos adultos às crianças é indispensável, devendo traduzir-se em uma mediação reflexiva, minimamente invasiva, que implique a observação e auxílio a cada uma delas em seus propósitos específicos, na interação efetiva com cada uma, proporcionando-lhes mergulhar nos papéis que escolhem representar na ambiência da sala tematizada e garantindo-lhes um suporte às suas descobertas, produzidas de forma autônoma. Esta prática deve orientar-se sempre por meio de "estratégias de interação" (melhor explicitadas mais adiante), que subsidiem a aprendizagem ativa, a resolução de conflitos pelas próprias crianças e a construção de climas de apoio.

O elemento final da sequência planejar-fazer-rever equivale ao momento de reflexão pelas crianças sobre aquilo que realizaram no tempo de trabalho. Assim, no espaço do 'rever', as crianças são encorajadas a relembrar suas ações e experiências - refletindo sobre elas-, a associar planos, ações e resultados, a falar sobre momentos específicos que lhes acrescentaram algum significado pessoal, a formar imagens mentais e falar a respeito e, por fim, a expandir a consciência para além do presente.

Voltar-se sobre intenções iniciais, associar planos com ações e resultados correspondentes e falar com os outros sobre experiências significativas são segmentos cruciais para o desenvolvimento intelectual e sócio-emocional de qualquer indivíduo, não sendo um aspecto exclusivo do aprendizado das crianças. Tais processos mentais e sociais possibilitam-nos buscar no passado pistas para o presente e para o futuro. Portanto, relembrar e 
refletir a respeito de acontecimentos e experiências vivenciadas é uma capacidade que ajudará as crianças no decurso de suas trajetórias pessoais (HOHMANN e WEIKART, 1997).

A consolidação do ciclo planejar-fazer- rever com as crianças e suas respectivas professoras na Sala de Áreas se deu a partir do estabelecimento dos três momentos previstos na rotina: um primeiro, do planejamento (10 a 15 minutos), efetuado em roda de conversa, no qual as crianças falavam sobre o que pretendiam fazer na sala; posteriormente, um momento de efetivação dos planos de brincadeiras (20 a 30 minutos), durante o qual as crianças circulavam na sala - em grupos ou isoladamente, à sua escolha -, passando pelas diferentes 'áreas de interesses' dispostas e interagindo com seus materiais; e, por fim, um momento (10 a 15 minutos), também em roda de conversa, de reflexão e discussão acerca do que cada um havia feito na sala naquele dia. Todos estes momentos, nas sessões iniciais de implementação da sequência, foram conduzidos por nossa equipe de estagiárias. Porém, esta tarefa foi aos poucos sendo atribuída às professoras, considerando-se o critério de já se sentirem à vontade para fazê-lo.

Para o 'planejar', assim como para o 'rever', lançávamos mão sempre de alguns recursos estratégicos interacionais, a fim de possibilitar às crianças expressarem-se mais articuladamente e estabelecer a comunicação de modo geral. Alguns destes recursos, por exemplo, eram o "olho mágico", uma espécie de luneta 'encantada"' que 'ajudava a ver' a brincadeira pretendida para aquele dia; "o telefonema", que consistia em levar dois telefones para a sala (um para as crianças e outro para a condutora da atividade) e 'ligar' para cada um (a), conversando sobre seus planos para o momento do brincar; ou o "cartaz", que era exposto em um cavalete diante das crianças e no qual escrevíamos, a partir de suas indicações, aquilo que gostariam de fazer na Sala. 
Figura 3: Cartaz de planejamento das crianças do $2^{0}$ período $\mathrm{B}$.

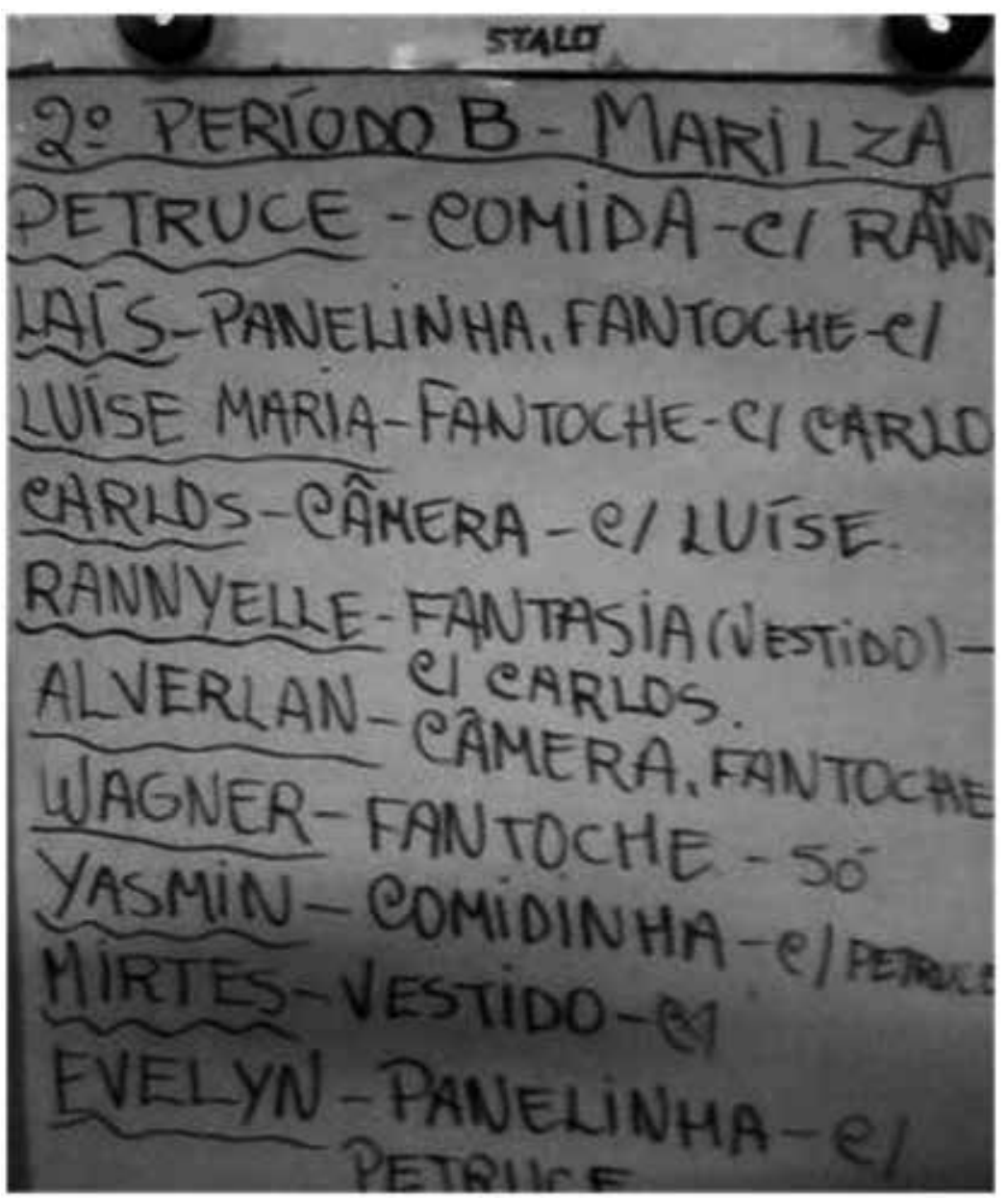

\section{Brincar de faz-de-conta e o letramento nas crianças}

"E o lobo mal se vestiu de chapeuzinho..." ('N', 4 anos)

O projeto de organização da Sala de Áreas na perspectiva da abordagem High/ Scope, em si, já se prenuncia como ferramenta favorável à promoção da aprendizagem, fornecendo às crianças subsídios diversos (materiais ou didáticos) que lhes proporcionem experiências significativas e a oportunidade de desenvolvimento em suas múltiplas dimensões e linguagens.

Conforme explicitado anteriormente, na Sala de Áreas organizada na escola foram dispostos vários ambientes específicos, com os quais pretendia-se oferecer às crianças 
uma aproximação a situações reais ${ }^{5}$ que, em geral, vivenciamos no dia a dia em nossa sociedade ${ }^{6}$ e, acima de tudo, robustecer sua expressividade através dos mecanismos de ludicidade ali contemplados. Dentro deste contexto, evidencia-se a aprendizagem propulsionada pela ação, pelo contato direto com materiais e pessoas (adultos apoiantes mediadores do processo de aprendizagem e as outras crianças envolvidas) e, ainda, pelas inúmeras possibilidades a serem descobertas no espaço proporcionado.

Do que pudemos observar como partícipes desta experiência, todos os ambientes dispostos na Sala mostraram-se potencialmente fecundos por favorecer o desencadeamento de aprendizagens pelas crianças, inclusive por meio das articulações entre áreas diferentes, estratégia bastante explorada por todas as turmas.

No entanto, tendo em vista o objeto de estudo que elegemos para esta reflexão, queremos, a partir deste ponto, chamar a atenção para um aspecto em especial, que remete ao entrelaçamento entre o 'brincar de faz-de-conta', experienciado intensamente pelas crianças nesta proposta de trabalho, e os processos de letramento em constituição, vislumbrados a cada sessão realizada nesta ambiência específica.

Durante as etapas de execução do ciclo planejar-fazer- rever na Sala de Áreas, pudemos constatar inúmeros momentos que consideramos como indiciários da emergência de processos de letramento, estes acontecendo como um continuum às atividades letradas realizadas paralelamente nas salas de aulas das diferentes turmas.

A "área de leitura", especialmente, por suas especificidades", foi um dos cenários capitais para a concretização e evidenciamento destes processos.

\section{Figura 4: Área de Leitura na Sala de Áreas}

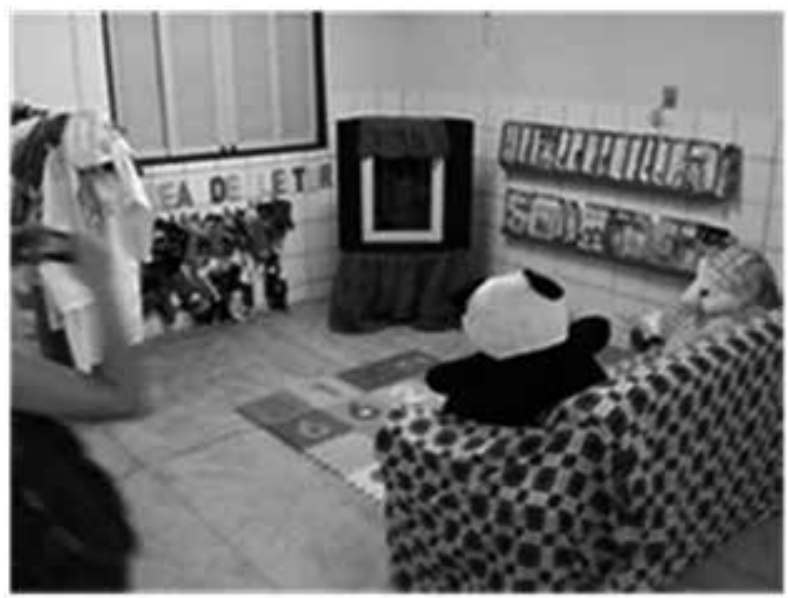


Neste espaço, as crianças, na maioria das vezes vestidas de princesas ou de piratas, de reis, rainhas... "fantasiadas" pela vestimenta (recurso da sala) e pela imersão no simbólico, dispunham de materiais impressos variados - livros de histórias infantis, clássicas e modernas, gibis, revistas, enfim, uma grande variedade de materiais portadores de textos, de "leituras a serem feitas" -, com os quais frequentemente estabeleciam contato, folheando-os, "lendo" ${ }^{8}$ suas linhas e suas imagens ou partilhando seu manuseio e suas "descobertas" com outros do grupo.

Entretanto, o simples contato com estes materiais por si só não é garantia de um processo de letramento efetivamente acontecendo. Por outro lado, as posturas que evidenciavam uma concepção do ato de ler ou de escrever como "um outro modo de dizer" (LEMOS, 1988, p. 11) - em que pese principalmente o fato de serem não alfabetizadas -, estas, sim, nos forneceram as pistas da condução deste processo nas crianças. Da mesma forma, as falas perceptivelmente perpassadas por um discurso escrito - "fala letrada" (ROJO, 1994) -, nas práticas mediadas por material impresso/escrito, permitiam-nos entrever as marcas do letramento em constituição naquelas crianças.

Desta forma, os diálogos que seguem expostos mais abaixo fornecem-nos um pequeno vislumbre dos efeitos ocasionados durante a experiência. Tais diálogos, vale destacar, representam apenas uma pequena amostra do vasto conjunto de "eventos de letramento" - eventos em que a linguagem escrita é essencial à natureza das interações e aos processos e estratégias interpretativas de seus participantes (HEATH, 1982, p. 50) - a que tivemos acesso. Dentro deste enfoque, é importante pôr em relevo ainda a importância que as crianças, durante a vivência experienciada, já atribuíam à linguagem escrita, e o reconhecimento mesmo em nível ainda bastante elementar que faziam de seus muitos significados e aplicações em nossa sociedade.

Quanto ao desenvolvimento da linguagem oral, em certa medida, também nos foi possível identificá-lo através desses momentos sobre os quais projetamos nossas análises. Nestes, uma e outra modalidade (escrita e oral) se misturam e se interpõem, seja nas narrativas expressas, nos diálogos, na discussão dos planos, seja nas muitas oportunidades abertas às crianças para que pudessem se expressar e trazer à luz seus posicionamentos e seus conhecimentos em elaboração, a partir da proposta efetivada.

Observemos, pois, os diálogos transcritos abaixo:

\section{Diálogo 1}

Duas meninas sentadas no tapete, na área de leitura, brincam com outras crianças. Então, resolvem "pegar um livro pra ler", cada uma. Assim, vão à estante de materiais impressos e escolhem os livros que querem, voltando à referida área. Uma das meninas, 'N', escolhe um livro que traz a história de "Chapeuzinho Vermelho". A outra levanta-se 
e retorna à estante. ' $\mathrm{N}^{\prime}$, então, abrindo o livro e colocando-se em 'postura de leitura', diz à coleguinha:

'N': "vem cá, ler comigo!"

Algumas crianças que brincam na máquina de escrever, localizada próxima à área de leitura, também se achegam para ouvir a 'leitura' da história pela colega. 'N' começa a história 'lendo' no livro ilustrado:

'N': "Uma vez, tinha uma vovozinha na casa dela e a netinha dela foi... (cantarolando) 'Pela estrada afora eu vou bem sozinha..."

A outra menina, 'L', volta ao tapete, olha o livro da colega e diz:

‘L': "ei, nãoé, não!"

'N': “é, sim! Ó, ó, se não é! (apontando no livro) 'Pela estrada afora eu vou bem sozinha...' Aí, ela encontrou um lobo... E depois, deixa eu ler (mudando a página), era um lobo maaaau, e ele comia, devorava as pessoas... Ele queria comer a Chapeuzinho Vermelho... (voz grave) Olha, chegou na casa da vovozinha! Ih, vai comer a vovozinha!... E ele se vestiu de Chapeuzinho!"

'L': "não, se vestiu de vovozinha!"

'N': "que orelhas grandes, vovozinha, você tem!... É para ouvir melhor! Eesses olhos, vovó, tão grandes?... É pra te enxergar melhor!... E esse, essa boca tão grande?... Queres saber, queres mesmo? Então, é pra te comer! E comeu ela!... (mudando a entonação) E ela foi correndo, e quando o caçador viu, matou o lobo!... (fazendo pausas para conferir as imagens do livro, parecendo guiar-se por elas) E ela foi amarrada!... E ela, depois... acaboooou!"

A esta altura, mais duas crianças já se uniram às duas meninas no tapete para ouvir sua história. ' $\mathrm{N}$ ' continua:

'N': "querem ler de novo? Então, tá! Todo mundo senta aqui no meu colo! (caindo na gargalhada)"

Os dois meninos que haviam se achegado levantam-se para sair da área de leitura. 'N' pede:

'N': "senta aqui!"

' $L$ ', desta vez, introduz a história imitando a postura da coleguinha. Ao final, após ter 'lido' a história por várias vezes para os colegas, quando todos saem do tapete, ' $\mathrm{N}$ ' põe um dos ursos do sofá para "escutar a história” que vai “ler" novamente.

Da observação destas falas transcritas e sua contextualização, podemos tecer alguns comentários. Percebemos que 'N', ao tomar um material impresso e, a partir dele, "ler" 
uma história para seus coleguinhas, busca colocar-se em uma posição "diferente", "legítima da leitura", isto é, não apenas aquela posição de alguém que vai "dizer algo" para outro alguém, mas sobretudo aquela de alguém que é capaz de "ler algo escrito" para outro alguém, e vai fazê-lo merecendo, por isto, a sua atenção. Tal posição é possivelmente modelada pelas atitudes de leitura da própria professora de ' $\mathrm{N}$ ' em sala de aula. Este "jogo de faz-de-conta" deixa rastros de um entendimento a respeito do ato de ler se constituindo e se revelando nas ações da menina, o que representa, como dissemos anteriormente, um "modo distinto" do "ato de falar". Essa distinção tem a ver exatamente com a capacidade do sujeito de se inscrever e de assumir uma posição neste sistema outro que é o sistema da escrita.

É notável ainda que 'N' não apenas descreve as ilustrações como também produz uma narrativa oral da história selecionada, agregando-lhe passagens que são verdadeiros extratos da narrativa clássica deste conto (Chapeuzinho Vermelho) nos livros de literatura infantil (observem-se as partes sublinhadas da transcrição). Estas marcas, definidas por Rojo (1994) como "fala letrada", demonstram o atravessamento de um discurso característico da escrita nas falas proferidas pela menina ao fazer sua "leitura" da história. Dizendo de outro modo, um processo de letramento desencadeado, muito provavelmente, pela participação da criança em momentos de contação de histórias - seja em contexto didático ou em contexto familiar, não há como precisar nesse momento - deixa-se entrever, como um continuum, nesta situação específica que descrevemos, e sua operacionalização se dá através da brincadeira de contar, favorecida pelo ambiente da sala.

Passemos, agora, à descrição de outra situação com a transcrição de um segundo diálogo, no qual encontramos também algumas pistas do letramento em curso a partir da experiência vivenciada.

\section{Diálogo 2}

$\mathrm{Na}$ área de casinha, uma menina, 'A', vestida com um jaleco de médica, diz para uma das estagiárias que é "médica de barriga". Desenvolve-se, então, um diálogo entre 'A' e a estagiária, 'E':

'E': "ah, doutora, eu vou me consultar com a senhora, porque eu tô com dor de barriga"

'A': "tá, pode vir!"

'E': "mas, onde fica a sua clínica?"

'A': "fica na rua..." 
A estagiária vai até a "doutora", que lhe examina. Em seguida, 'A' toma papel e caneta, e "escreve", rapidamente, a "receita" para sua "paciente:

'A': "pronto, tá aqui a receita! O nome do remédio é 'Gemipson' (apontando no papel que chama de receita e no qual 'escrevera')"

'E': "e é caro esse remédio?"

'A': "é dois reais, só!"

'E': "tá bom, então! Brigada, doutora A...!"

'A': "de nada!"

Diferentemente da primeira situação dialogal descrita, nesta segunda, queremos pôr em relevo o desencadeamento de um processo de letramento através da instanciação de um ato de escrita. A menina 'A', ainda não alfabetizada, assume um posicionamento legítimo de alguém que "sabe escrever", e atribui a esse ato uma função social específica: o (a) médico (a), que escreve uma receita para seu paciente.

Retomando as palavras de Calil (2004, p. 335), já mencionadas anteriormente, reconhecemos que "em uma sociedade letrada, os eventos de letramento são múltiplos e o sujeito está imerso em diferentes situações de uso significativo da leitura e da escrita". É sob esta perspectiva que podemos "ler" a atitude da menina 'A' e o significado que, no contexto referido, ela atribui à escrita: certamente ' $\mathrm{A}$ ' reflete, em suas ações, experiências anteriores nas quais já tenha sido imersa dentro deste mesmo contexto, tal como a visita real a um consultório médico, na qual o ato de prescrever uma receita tenha sido por ela presenciado. A vivência provável desta situação, em que um ato de escrita é significado socialmente, possivelmente instaura na criança uma perspectiva de letramento que é retomada durante este momento de brincadeira na Sala de Áreas. É importante, entretanto, sinalizar que o papel do adulto nesta conjuntura mostra-se fundamental, uma vez que na interação dialógica estabelecida entre ambos, criança e adulto, revela-se o "elemento viabilizador e impulsionador" do processo de letramento posto em ação durante a experiência.

Além destas ocasiões particulares que trazemos à análise, outras ainda podem ser destacadas, dentro do contexto de execução da rotina da abordagem High/Scope na Sala de Áreas da escola. Nos momentos relativos ao planejamento e à revisão das atividades (o primeiro e o último na sequência planejar-fazer-rever), inúmeras vezes foram postos em funcionamento mecanismos estratégicos que davam margem à mobilização de processos de letramento entre as crianças, se a estes os compreendemos, dentre outras acepções, como "resultados da ação de ensinar ou de aprender a ler e escrever", tal qual definido por Magda Soares (1996, p. 85), já antes referido. 
Sob este enfoque, ilustrativamente, houve momentos em que as crianças participavam da produção de cartazes nos quais eram transcritas, pelas estagiárias, as intenções de brincadeiras de cada um do grupo, durante a roda de conversa. Nestes momentos, que implicavam diretamente a produção escrita, as crianças mostravam-se bastante envolvidas, e interagiam, por exemplo, indicando "formas corretas ${ }^{9 "}$ ou alternativas para a inscrição de determinados excertos transcritos no cartaz, demonstrando assim que, para elas, aquela atividade possuía um sentido real e efetivo, voltado para as práticas letradas.

Todas estas situações, de um modo geral, convergem para um mesmo ponto: aquele em que objetos da escrita são investidos de significado através de práticas discursivas interacionais, das quais emanam dizeres, discursos, textos, letras..., assumindo o outro (o adulto ou a criança com quem se interage) um lugar de destaque nesta interação (CALIL, 2004, p. 335). É importante ressaltar ainda o papel estruturante e vital que o brincar, o "fazer-de-conta" assume nestas experiências, consignando-lhes os elementos necessários para sua efetivação e atribuindo-lhes os contornos que tornam possíveis as aprendizagens vislumbradas.

\section{Considerações finais}

O trabalho com a educação infantil e, especificamente, com crianças revela-se sempre surpreendente. Para nós, diríamos ainda, traduz-se sempre em algo verdadeiramente inspirador. Desta feita, a experiência vivenciadanesta pesquisa foi de grandeimportância para nossa formação, oportunizando-nos adquirir aprendizagens essenciais para a nossa atuação profissional.

Assim, nos foi possível compreender o valor do aprendizado a partir de experiências significativas, criando-se condições favoráveis para o desenvolvimento e a conquista da autonomia pela criança, diante do objeto de conhecimento a ser assimilado, o que, como observado, depende substancialmente também do papel e da postura assumida pelo educador com quem ela interage.

Do que nos propomos investigar, percebemos que no terreno da brincadeira processos de aprendizagem podem tomar lugar, notadamente quando se estabelecem os jogos de "faz-de-conta" entre as crianças, nos quais a imaginação e a fantasia lhes servem de recurso para assumir posições que, fora disto, ainda lhes seriam inalcançáveis. Da mesma forma, o letramento, longe de ser algo determinado a priori, corresponde a um processo que está intimamente ligado a uma série de outros - sócio-históricos, subjetivos, didáticos, linguísticos... para citar alguns; e, por isto mesmo, deve ser encarado como um fenômeno multifacetado (SOARES, 1998), carregado de possibilidades.

Compreendemos, sobretudo, que aliar o processo de letramento à brincadeira e aos jogos de "faz-de-conta", especialmente na educação infantil, pode potencializar o próprio processo de aquisição da linguagem pela criança, favorecendo todo o seu desenvolvimento, pois, trata-se de um elemento que diz de sua própria natureza, lheé constitutivo, lhe é reconhecível. 
Recebido em: 25/06/2018 e aprovado em: 17/08/2018

\section{Notas}

1 Originária da cidade de Ypsilanti, Michigan, nos Estados Unidos.

2 Assim é denominado, no High/Scope, este espaço específico de trabalho com as crianças.

3 Terminologia proposta nas diretrizes da abordagem High/Scope.

4 Tratava-se de um rolo de papel higiênico trabalhado e decorado de forma a se assemelhar a uma luneta. A "mágica" estava no jogo de faz-de-conta que propúnhamos, dizendo às crianças que o objeto era encantado e possuía poderes especiais, na tentativa - na maioria das vezes, bem sucedida - de imergi-las em um contexto de descontração e maior abertura ao se expressarem.

5 Simuladas na ambiência da sala.

6 No ambiente da casinha, por exemplo, havia fogão e geladeira de brinquedo, em tamanhos próximos à estatura média das crianças, panelinhas, mesa e cadeiras para as refeições, um vestuário para as crianças se ornamentarem com acessórios e fantasias diversas à sua disposição (jalecos de médico, roupas de palhaço, pirata, vestidos de princesas, príncipes etc.), dentre outras possibilidades.

7 Neste ambiente, foram disponibilizadas, em uma estante acoplada à parede, várias obras de literatura infantil, sobretudo contos da literatura clássica ("Chapeuzinho Vermelho", "Os Três Porquinhos", "Cachinhos Dourados", para citar alguns). Dispusemos também um tapete e almofadas para as crianças assentarem-se no chão, bem como um sofá e alguns bichos de pelúcia para que pudessem realizar suas 'leituras' de modo confortável. Havia ainda neste 'cantinho' - como também é chamada cada área de interesse - alguns fantoches e um 'teatrinho' para as crianças que quisessem produzir alguma encenação.

8 O destaque aqui se dá pelo fato de que este trabalho se alicerça sob o terreno da educação infantil e, assim sendo, as crianças nesta experiência ainda não estavam convencionalmente alfabetizadas, não lhes sendo possível, portanto, efetivar um ato de leitura "literal", ou seja, alfabética.

9 Às vezes, intencionalmente, as estagiárias pronunciavam alguma palavra ou expressão de forma errada, fingindo que a escreveriam dessa forma no cartaz. As crianças, por sua vez, faziam intervenções imediatas, indicando a forma correta que conheciam (considerando que ainda não estavam alfabetizadas) de se escrever tal palavra ou expressão.

\section{Referências}

BRASIL, Ministério da Educação e do Desporto. Secretaria de Educação Fundamental. Referencial Curricular Nacional para a Educação Infantil - 1V. Brasília: MEC/SEF, 1998.

BRICKMAN, Nancy; TAYLOR, Lynn. Aprendizagem Ativa. Lisboa: Fund. Calouste Gulbenkian, 1996.

CALIL, Eduardo. Marcas de letramento: efeitos equívocos de um funcionamento. In: GERALDI, Corinta; RIOLFI, Cláudia; GARCIA, Maria de Fátima. (Orgs). Escola Viva: elementos para a construção de uma educação de qualidade social. Campinas: Mercado de Letras, 2004. p. 333-353.

HEATH, Shirley. What no bedtime story means: narrative skills at home and school. Language in Society, Nova York, Cambridge University Press, v. 11, n. 2, p. 49-76, 1982. 
HOHMANN, Mary; WEIKART, David. Educar a criança. Lisboa: Fundação Calouste Gulbenkian, 1997.

KISHIMOTO, Tizuko. O brincar e a emergência da linguagem (letramento). In GERALDI, Corinta; RIOLFI, Cláudia; GARCIA, Maria de Fátima. (Orgs.). Escola Viva: elementos para a construção de uma educação de qualidade social. Campinas: Mercado de Letras, 2004. p. 355-370.

LEMOS, Cláudia. Prefácio. In: KATO, Mary. (Org.). A concepção da escrita pela criança. Campinas: Pontes, 1988.

ROJO, Roxane. A noção de fala letrada: implicações psicolinguísticas. In: ESTUDOS LINGUÍSTICOS XVIII, 1994, Ribeirão Preto. Anais de Seminários do GEL, Ribeirão Preto: GEL, 1994, p. 51-58.

SOARES, Magda. Letramento/alfabetismo. Presença Pedagógica, Belo Horizonte, Ed. Dimensão, v. 2, n. 10, p. 83-89, jul./ago., 1996.

. Letramento: Um Tema em Três Gêneros. Belo Horizonte: Autêntica, v.1, 1998. 